\title{
Structural Analysis of W7-X: Main Results and Critical
}

\section{Issues}

$\underline{\text { V.Bykov }}^{\text {a }}$, F.Schauer ${ }^{\text {a }}$, K.Egorov ${ }^{\text {a }}$, P.van Eeten ${ }^{\mathrm{a}}$, C.Damiani ${ }^{\mathrm{a}}$, A.Dübner ${ }^{\mathrm{a}}$, M.Sochor ${ }^{\mathrm{a}}$, L.Sonnerup $^{\mathrm{a}}$, A.Capriccioli ${ }^{\mathrm{c}}$, A.Tereshchenko ${ }^{\mathrm{a}}, \mathrm{N}^{-J a k s i c}{ }^{\mathrm{b}}$, W.Dänner ${ }^{\mathrm{a}}$, M.Rumyancev ${ }^{\mathrm{a}}$, D.Zacharias $^{\text {a }}$

${ }^{a}$ Max-Planck-Institute für Plasmaphysik, Euratom Association, Teilinstitut Greifswald, Wendelsteinstrasse 1, D-17491 Greifswald, Germany

${ }^{b}$ Max-Planck-Institut für Plasmaphysik, Boltzmannstraße 2, D-85748 Garching, Germany ${ }^{c}$ C.R.E. ENEA Frascati, Via Enrico Fermi 45, 00044 Frascati (Roma), Italy 
Abstract- The Wendelstein 7-X (W7-X) stellarator project goal is to demonstrate that the stellarator is a viable option for a fusion power-plant. W7-X is in an advanced state of construction and has entered the assembly phase in at the Max-Planck-Institute für Plasmaphysik (IPP) in Greifswald, Germany.

The W7-X “pentagonal” basic magnet system is highly sensitive to parameter variations; the cryostat comprises two vessels, which are interconnected elastically by 299 ports. The strategy of the structural analysis for this complex mechanical system is being developed and implemented with the ultimate goal to create a tree of numerical models which reliably predict the stellarator structural behaviour.

This paper gives an overview of the strategy, addresses the critical issues and focuses on the most interesting results of the analyses.

Keywords: Stellarator, WENDELSTEIN 7-X, Finite-Element Analysis 


\section{Introduction}

WENDELSTEIN 7-X (W7-X) will be the largest stellarator in the world with an average major radius of $5.5 \mathrm{~m}$, an average minor radius of $0.53 \mathrm{~m}$ and a total weight of $725 \mathrm{t}$. It shall operate at reactor relevant plasma parameters [1], [2].

The main structural components of W7-X are the magnet system, the cryostat system comprising the plasma vessel, the outer vessel and the ports, and the machine base (MB) (fig. 1).

The Plasma Vessel (PV) closely follows the twisted shape of the plasma and is manufactured from stainless steel (SS) segments $17 \mathrm{~mm}$ thick. 299 ports with different shapes (round, oval, rectangular) connect the PV to the Outer Vessel (OV). The superconducting magnet system is located between the PV and the OV and kept at cryogenic temperature (4K) in high vacuum ( $\left.10^{-4} \mathrm{~Pa}\right)$

A reliable prediction of the W7X structural behaviour is only possible with extensive Finite Element (FE) analyses. The main activity is currently focused on the magnet system, which is a challenging task due to the complexity of the coil geometries and the nonlinear behaviour of the coil support system. The whole structure is highly sensitive to initial contact gap widths, contact friction factor, coil stiffness, bolt pretension, etc. The global cryostat system FE model is in advance state of development. It includes the OV, the PV, the ports with bellows and the MB. An independent analysis of the components without taking into account their interactions would not be accurate enough. 


\section{Strategy of Structural Analysis}

\subsection{Finite Element Analysis strategy}

The ultimate goal of structural analysis is to create a global model of the W7-X machine with a tree of numerical models for each subsystem and critical components. This approach allows to reliably predict the stellarator structural behaviour, to establish limits for machine operation and to adopt new plasma scenario and operational regimes. FE global models for the magnet system and for the cryostat system are considered separately. The small interaction between them is simulated by application of forces and moments generated by the magnet system to the machine base and to the OV in the cryostat FE global model.

The strategy of the W7-X structural analysis [9] is similar to the approach for many other unique and large facilities. Two types of models are intensively used: global models (GMs) for the choice of main system parameters and local models for detail analysis of the critical components. The intention to avoid any mistakes in the magnet system analysis and to verify the results requires to have several completely independent FE models. This approach results in a correction of inaccuracies in all models, in clearly defined boundary conditions, and in a confirmation of main parameters.

\subsection{Structural design criteria}

Main issue is the choice of structural design criteria for the cryogenic magnet system. In general, the criteria follow the ones developed for the ITER project with exceptions for 1) 
structural welds and 2) structure components with significant plastification.

A weld efficiency factor of 0.85 has been approved for all welds on the basis of a wide program for welder qualification and of weld material tests.

For components with high plastic strain, a special elasto-plastic limit analysis has been developed in collaboration with Ljubljana University (Slovenia) and Forschungszentrum Jülich (Germany). The method includes degradation of stainless steel properties due to a possible “serration effect” (see e.g. [11]) in case of exceeding the level of 1\% plastic strain. Safety margins of 2 and 1.5 are applied to estimated limit loads for normal and abnormal cases respectively. 


\section{W7-X magnet system}

\subsection{Coil configuration and supports}

The W7-X magnet system consists of 50 superconducting non-planar coils (NPC), 20 superconducting planar coils (PLC) and the mechanical structure, which is based on the central support structure (CSS) and the intercoil support structure. The CSS is fixed to the MB by ten cryolegs. The NPCs have complex 3D geometry to ensure the required magnet field configuration (figs. 2, 4). The coils are arranged toroidally in five equal modules, with each one consisting of two symmetric semi-modules. One semi-module includes five differently shaped NPC and two PLC (fig.4).

The winding packs (WPs) of the PLC and NPC are enclosed in 316 LN stainless steel casings in order to withstand the high electromagnetic (EM) forces applied to the coils. The NPC casing is made by two cast half-shells which are welded together. The PLC casing is made of welded plates to form two side walls which are closed by two lids and joined by bolts and pins.

The detail design of the mechanical system (fig.2) has been subjected to considerable modifications over the years [3], [4], [6]. Now the design is being finalised, which fulfils the requirement of a dimensional accuracy to be reached and complies with the limited available space and the high EM loads. Each NPC and PLC is fastened to the CSS by two central support elements (CSE). The CSE is a bolted connection with a possible opening of the flange. The narrow support elements (NSE) and the lateral support elements (LSE) connect adjacent NPC casings in the inboard and outboard region of the machine respectively. The 
NSEs are sliding contacts, while LSEs are welded connections with the exception of the intermodule ones which are designed as bolted connections. The planar supports elements (PSE) connect the PLC to the NPC. The design of PSEs is under revision now.

\subsection{Global models}

The GMs are extensively used for thermal and mechanical analysis and to extract the boundary conditions in terms of displacements or loads and moments for separate detailed analysis in critical areas

The present choice of the $72^{\circ}$ module for the FE global analysis is mainly done in accordance with the W7-X assembly procedure. The only requirement for the selection of the module separation surfaces for FE analysis purposes is to extract the cyclic symmetrical part of the machine. Moreover, the analysis of the magnet system under EM loads during normal operation can properly be performed on a regular semi-module [5]. Both the geometry and the EM loading satisfy such "stellarator" boundary conditions, which is a $180^{\circ}$ flip symmetry of adjacent semi-modules. Their separation surfaces are set up outside sliding or contact interactions and pre-tension elements. The main requirements for the semi-module boundary conditions are specified in [9]. Most of the analysis has been performed on a $36^{\circ}$ model [6, 9]. However, the presence of the cryolegs and the influence of the deadweight can only be analysed with a $72^{\circ} \mathrm{FE}$ model (see fig. 4).

The first GM was created at IPP Garching in 1992 with the ADINA FE code. The ADINA GM has been intensively used to define the main parameters of the machine [7],[8] and has 
been subjected to continuous modifications in line with the magnet system design evolution. The second GM has been created with the ANSYS code in collaboration with Efremov Institute (Russia) in 2004. In parallel to modification work on the ADINA GM, a third GM with the ABAQUS code has been created in collaboration with LTC company (Italy) in 2006 as an extension of already available FE models for the coils and mechanical structure.

\subsection{Global analysis}

The high number of sliding contacts and the opening of some of the CSE flanges make the magnet system behaviour highly non-linear. Moreover, the requirements for a limitation of the loads and moments on the support structure and the restriction of component movements dictate the choice for a special gap variation for the NSEs ranging from 0 to $4 \mathrm{~mm}$ in order to put them in contact from the beginning and/or at different times during magnet energizing. An uncontrolled initial gap distribution results in jumping of forces from one contact support to another and in considerable exceeding of allowable design loads of 1.5 $\mathrm{MN}$ and 1.0 $\mathrm{MN}$ for NSEs with $73 \mathrm{~mm}$ OD and $60 \mathrm{~mm}$ OD pads, respectively. Besides that, it influences the forces and moments transferred via the CSE and the LSE. The installation of at least two NSEs with zero gap between neighbouring NPCs reduces the assembly tolerances and improves the prediction of the system behaviour. The recommended NSE gap distribution between NPC3 and NPC4, to be assembled in autumn 2006, and expected NSE forces are presented in Table 1. A variation of the optimized gap distribution with the expected inaccuracy in coil positioning up to $0.8 \mathrm{~mm}$ results in about $30 \%$ changes of forces for critical NSEs, which is fully covered by a margin applied to the NSE design. The studies on the influence of variation 
of bolt preloads, of material properties, the NPC case thickness, and of other parameters on the redistribution of the forces and moments in critical support are still to be finalized. The current design loads for LSE and CSE with a margin of $20 \%$ to cover the remaining uncertainties are summarized in Tables 2 and 3, respectively.

The benchmarking of the ANSYS GM model with the ABAQUS GM is still in progress. However, preliminary results indicate that forces and displacements for most of the critical components are in agreement within 10-15\%.

The presence of the cryolegs and the deadweight result in 5-20\% asymmetry in the displacements and support forces between neighbouring 36-degree semi-modules. In addition, the rigid body toroidal movement of the Magnet system has been estimated.

\subsection{Local analysis}

A considerable number of local models has been created to analyze critical components of the machine. Planar coils, structural welds, planar supports, lateral supports, cryolegs, etc. are investigated at IPP. However, most of the local analyses are carried out in collaboration with sub-contractors in the framework of national and international contracts:

- Forschungszentrum Jülich (Germany): narrow supports, bus system,

- Warsaw University of Technology (Poland): central supports,

- CEA, CRIL Technology (France): central support structure,

- ENEA (Italy): lateral supports for inter-module and semi-module interfaces,

- Efremov Institute (Russia): planar support B1, semi-module contact supports,

- Ljubljana University (Slovenia): narrow supports, 
- etc.

The results of the GM analysis have been transferred to the local models in terms of forces and moments (fig. 6), or in terms of displacements in case sub-modelling procedures are used (fig. 5, 7). The application of the sub-modelling procedure requires special attention in the case of contact/gap elements inside the sub-model. Reliable results can only be achieved in case of proper application of the displacement history.

The local analysis reveals that some components of the magnet system have to be reinforced by ribs, additional welds, pins or shear keys. The modifications were implemented in the production process. 


\section{W7-X cryostat system}

During the design phase 1999 - 2003 the components of the cryostat system have been modelled and analysed separately. The interaction between the components has been simulated by application of estimated forces or by full fixation of boundaries. This approach is not very accurate and could result in some errors concerning extraction, interpretation and application of the interaction forces.

The first FE model comprising three interconnected main components (the PV, the OV and the MB) was created in 2005 (see fig. 8) with the main purposes to analyse on the one hand more accurately the MB to be procured, and on the other hand an auto-centering system and a horizontal fine adjustment system for the PV. The FE model has been based on available FE models for the PV and the OV created in 2001 and 2003 respectively, and was set up as a repetition of the first sector of each vessel. Due to the interconnection by 299 ports with bellows, and the relatively high flexibility of the vessels, the accurate definition of bellows stiffness for all 16 types has a high priority. The stiffnesses of bellows have been calculated with refined FE models (see e.g. fig. 9) and confirmed later by experimental results for a rectangular bellows [10]. The final revision of the cryostat GM is to be completed in collaboration with ENEA (Italy) in autumn 2006. The updated FE model of the OV has been created by IGN company (Germany), which is currently updating that of the PV.

The modified OV and the MB FE models have been used for the confirmation of the buckling stability of the OV under different loading conditions. The linear and nonlinear 
buckling analyses confirm that load amplification factor (LAF) above 4.5 is typical for the OV (see fig. 10).

The global analysis of the cryostat system is to be followed by local analyses of critical components in order to confirm the structural reliability of the system. The main attention has to be paid to port welds and vessel supports. 


\section{Conclusions}

Resolving the main critical issues in the W7-X design is only possible with an accurate prediction of the system structural behaviour.

Difficulties concerning the magnet system analysis derive mainly from the complexity of the coil geometries, and the high sensitivity to any parameter variation, which is due to sliding coil supports, opening of flange connections, and sliding of winding packs.

A strategy for extensive FE structural analyses has been developed and is being used to validate the adopted design solution and to perform the proper choice of parameters still to be adjusted. The partially created FE model tree also provides the possibility to quickly analyze non-conformities reported by manufacturers, and to accept or reject inconsistencies with the reference design. 


\section{References}

[1] V. Erckmann et. al., “The W7-X Project: Scientific Basis and Technical Realisation,” $17^{\text {th }}$ IEEE/ NPSS Symposium on Fusion Engineering, Vol. I, San Diego California, October 610, 1997, pp. 48-48.

[2] F. Schauer et. al., "Status of Wendelstein 7-X Construction”, 24th SOFT Symposium on Fusion Technology, Warsaw, September 11-15, 2006, to appear

[3] M. Gasparotto et. al., "The WENDELSTEIN 7-X Mechanical Structure Support Elements: Design and Tests"”, Proc. of the $23^{\text {rd }}$ symposium on Fusion Technology (Venice 2004), to appear

[4] M. Gasparotto et. al., “Critical Design Issues of Wendelstein 7-X,” 15th International Stellarator Workshop 2005, to appear.

[5] N. Jaksic et. al., Defnition der Randbedingungen bei einer FE-Strukturanalyse durch Nutzung der Symmetriebedingungen einer Stellaratoranordnung,“ IPPZ/3, February 1997.

[6] C. Damiani et. al., "Design and development of the Wendelstein 7-X inter-coil supports: main results and critical issues”, 24th SOFT Symposium on Fusion Technology, Warsaw, September 11-15, 2006, to appear

[7] N. Jaksic and J. Simon-Weidner, "Design analysis of the support structure stressed by large superconducting coils for a plasma fusion experiment”, Computers and Structures 81 (2003) 697-714.

[8] N. Jaksic and J. Simon-Weidner, "Nonlinear global-local finite element analysis of a future plasma fusion experiment,” Computers and Structures 72 (1999) 209-231.

[9] V. Bykov, et al, "Strategy of Structural Analysis of W7-X Magnet System “; Proc. 21. IEEE/NPS Symposium on Fusion Engineering 2005 (CD-Rom), IEEE 2006, paper 04_11. 
[10] J. Reich, et al, "Experimental verification of the axial and lateral stiffness of large W7-X rectangular bellows”, 24th SOFT Symposium on Fusion Technology, Warsaw, September 11-15, 2006, to appear.

[11] T. Ogata, K. Ishikawa, Discontinuous Deformation During Load and Displacement Controlled Tensile Tests and Optical Observation in Liquid Helium, Cryogenics, 28, 511518, 1988 
Figures

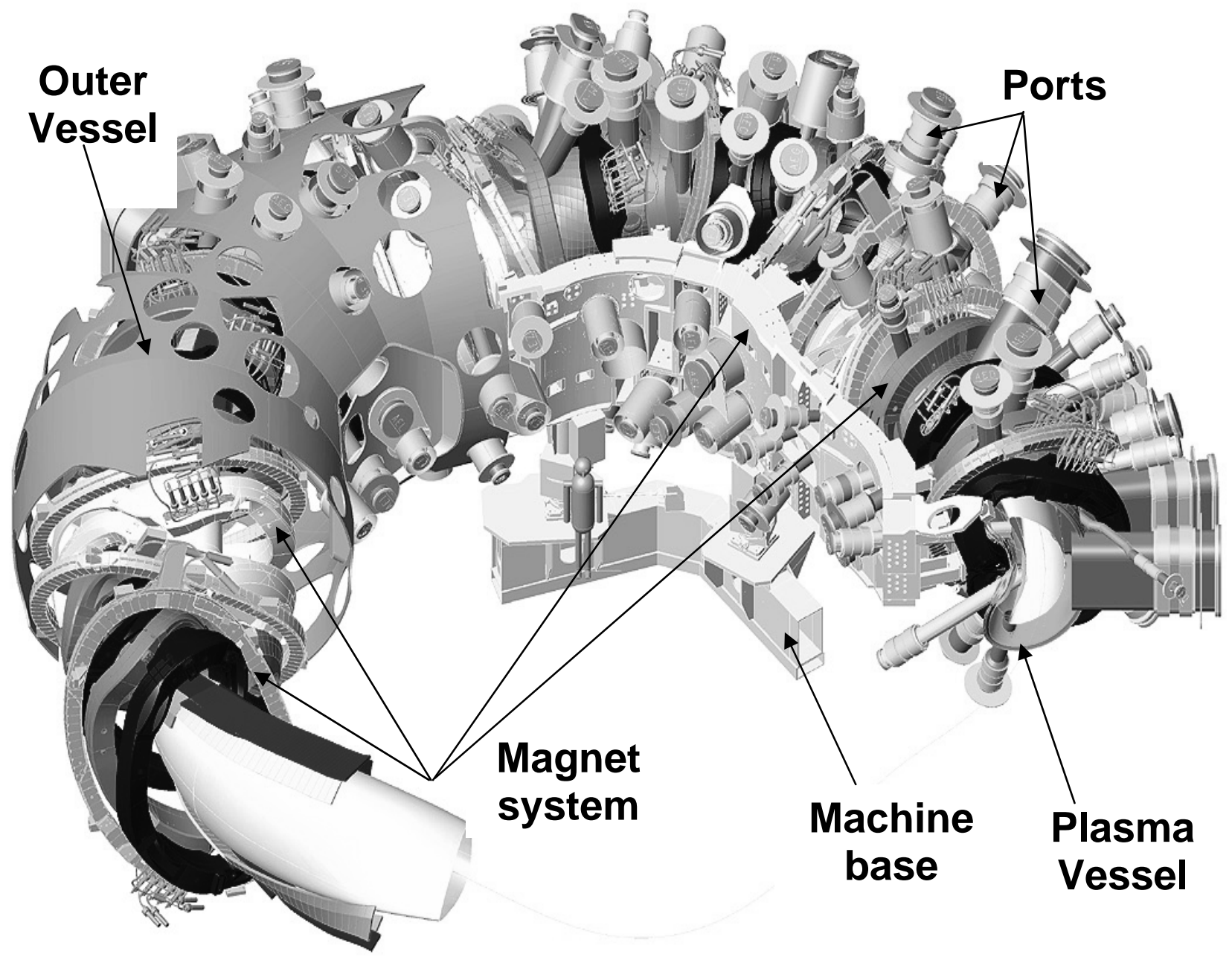

Figure 1. CAD view of WENDELSTEIN 7-X 


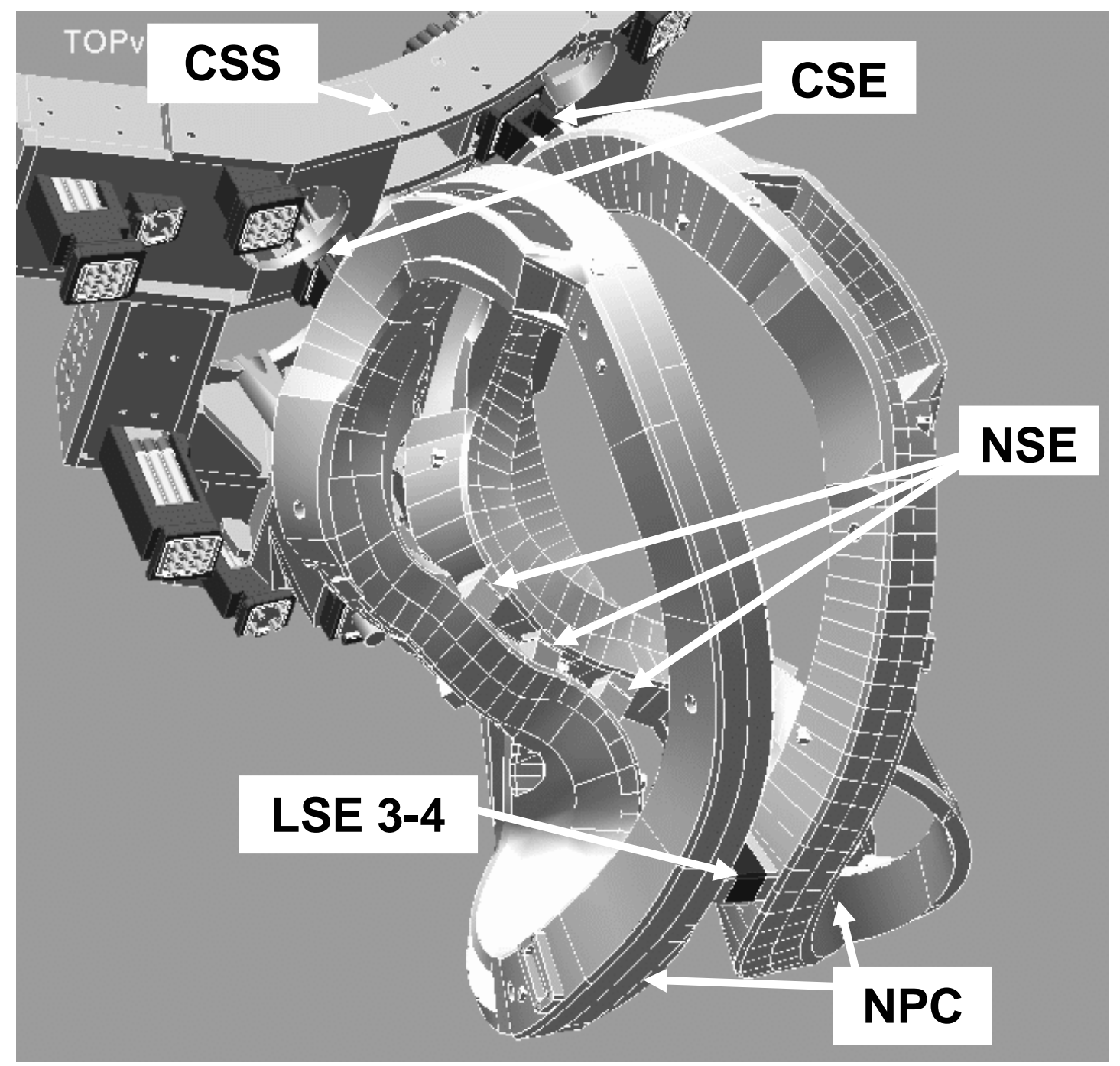

Figure 2. Support structure for NPCs type 3 and 4 


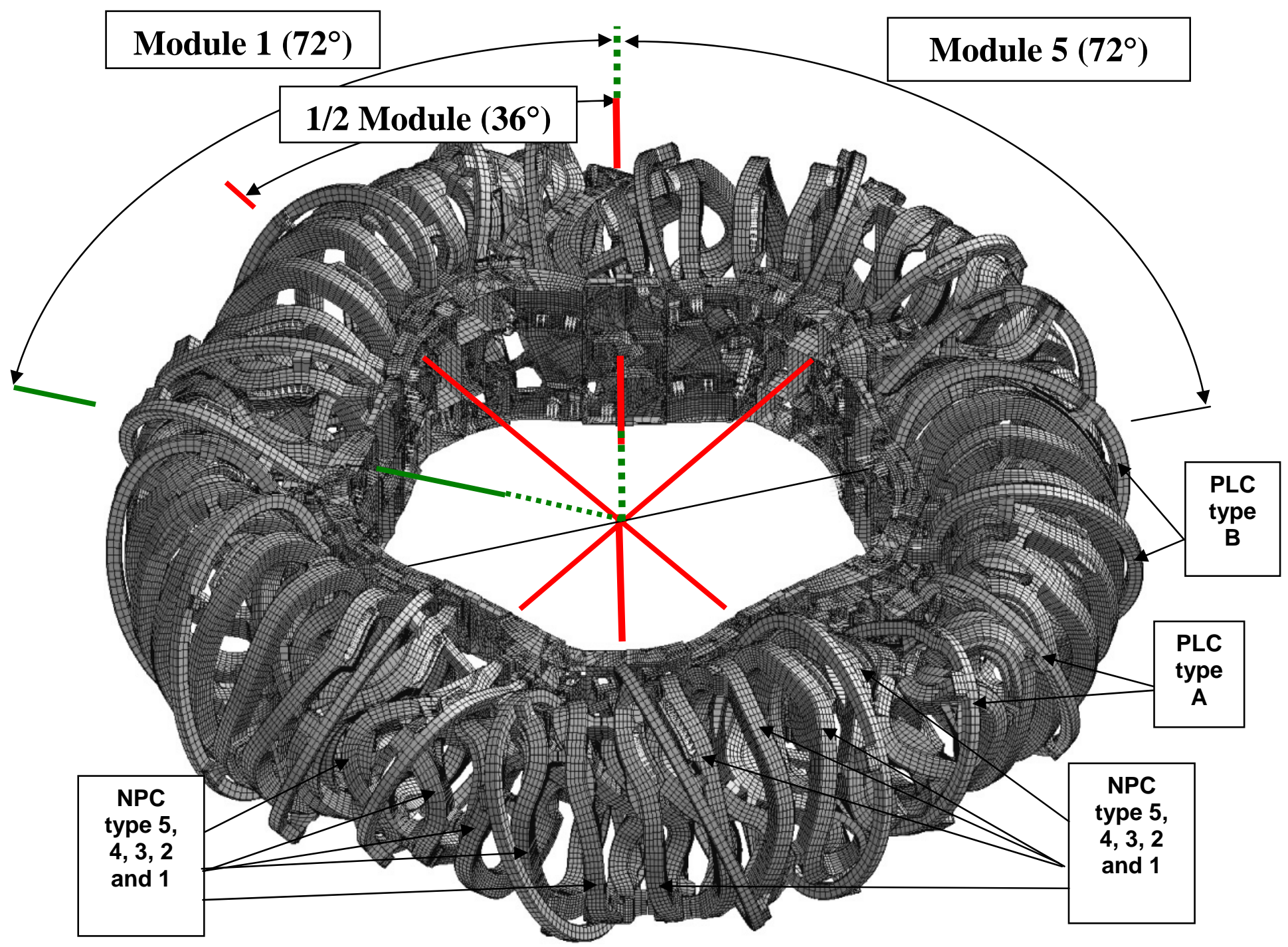

Figure 3. ADINA $360^{\circ}$ FE Global Model. W7-X symmetry. 


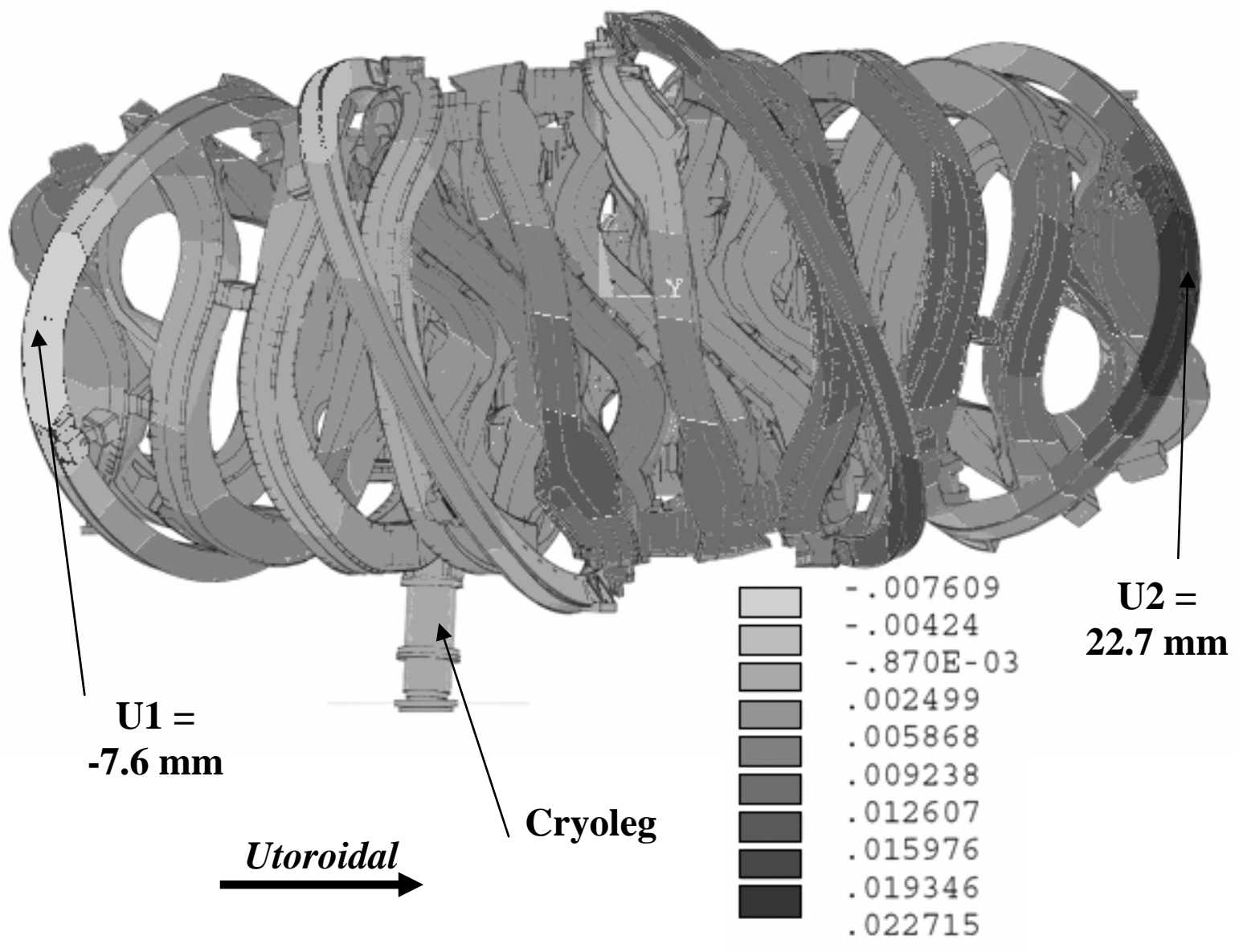

Figure 4. Toroidal movement of magnet system in case of 5 cryolegs and 0.2 friction factor in NSEs, m. $72^{\circ}$ FE model with cyclic boundary conditions: bolt preload, cooldown, deadweigt and EM forces due to High Iota plasma regime. 

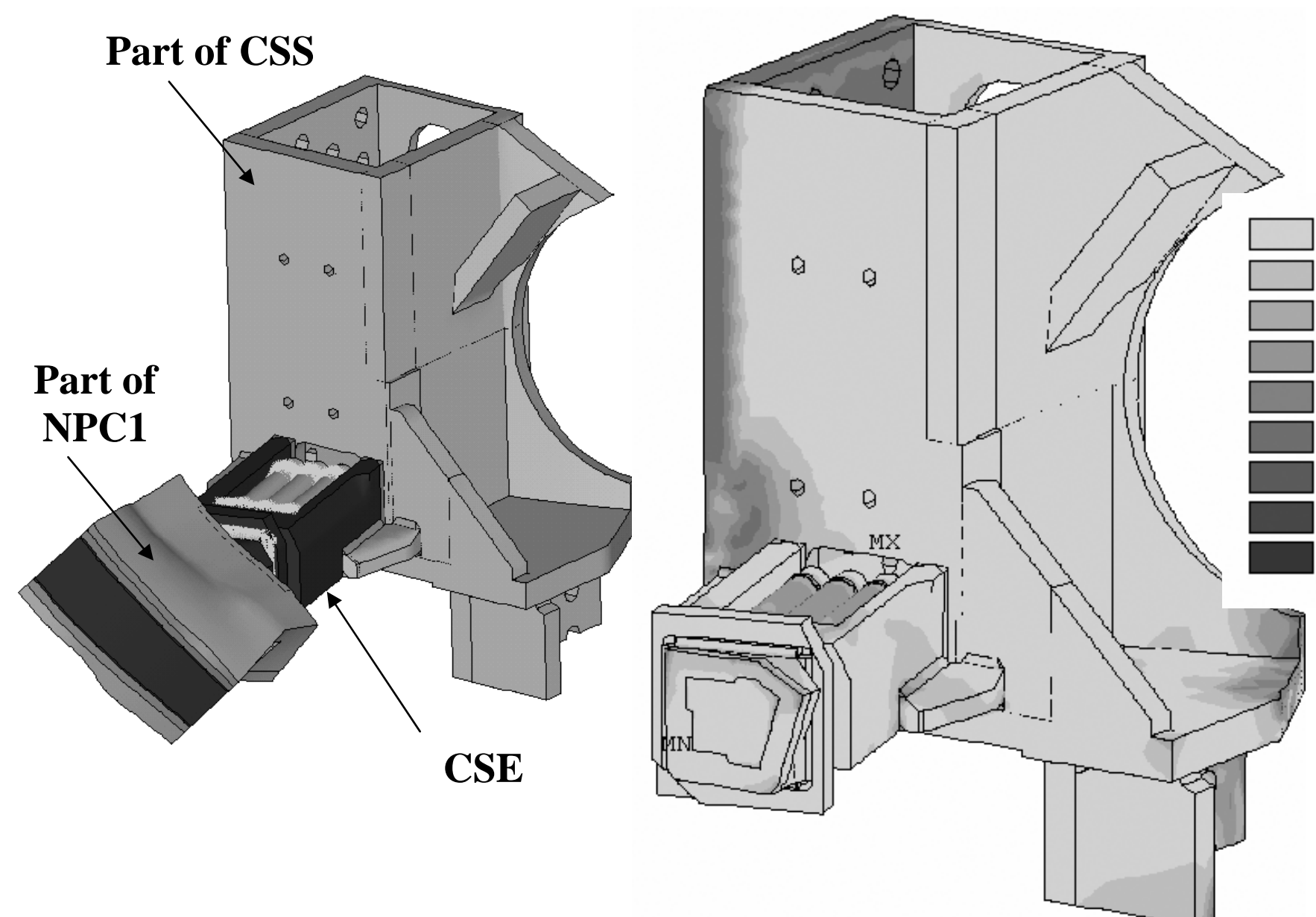

.30935

198.196

396.083

593.97

791.857

989.744

1188

1386

1583

1781

Figure 5. Sub-modelling analysis of NPC1 bottom CSE (Warsaw University of Technology,

Poland): Von Mises stress, MPa. 


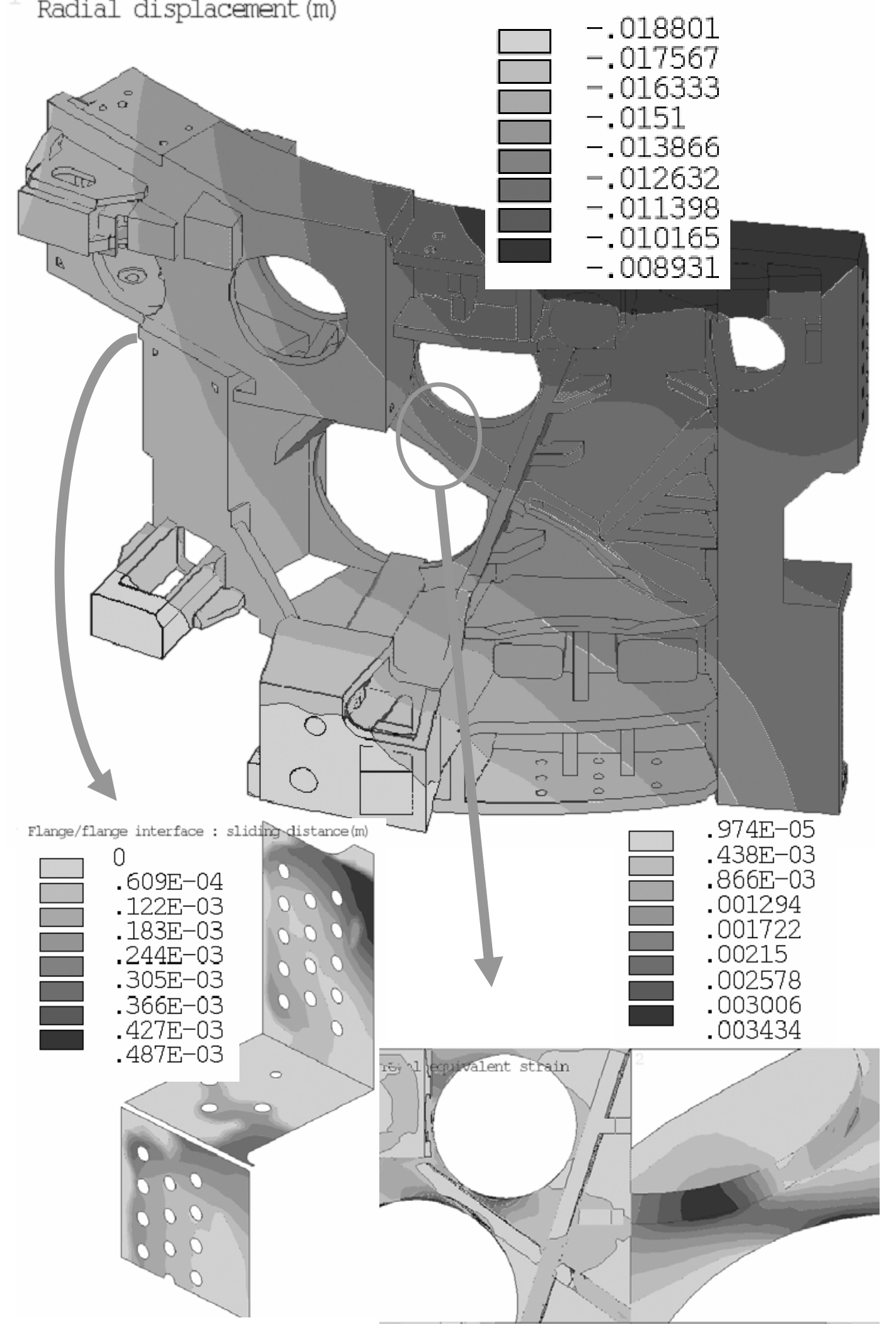

Figure 6. Elasto-plastic analysis of Central Support structure semi-module under forces and moments from GM (CEA/CRIL Technology, France): Radial displacement, m; local sliding in stepped flange, m; total strain in critical region. 

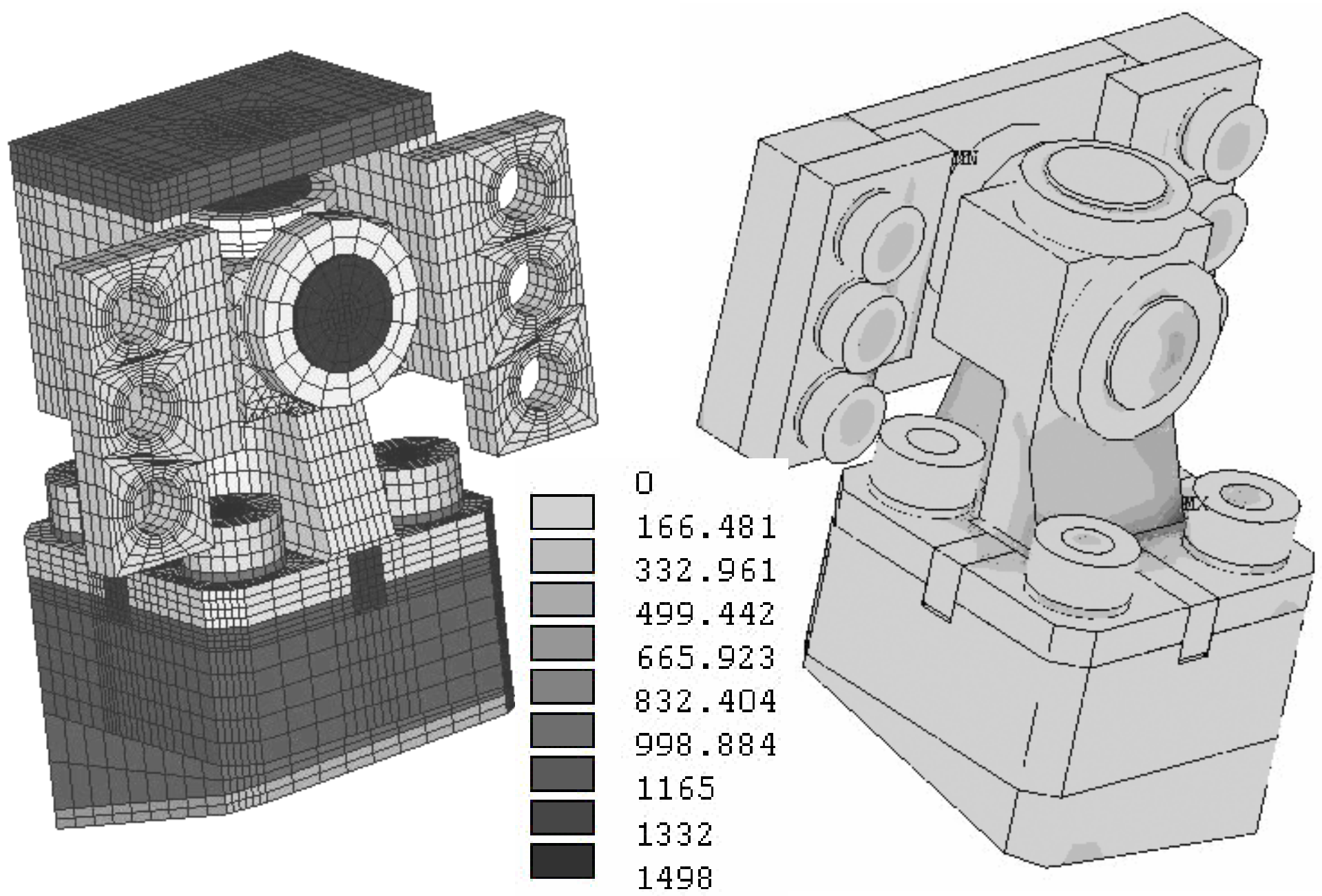

Figure 7. Sub-modelling analysis of Planar Support B1 (Efremov Institute, Russia): Fragment of FE mesh. Stress intensity distribution in the central part, MPa 


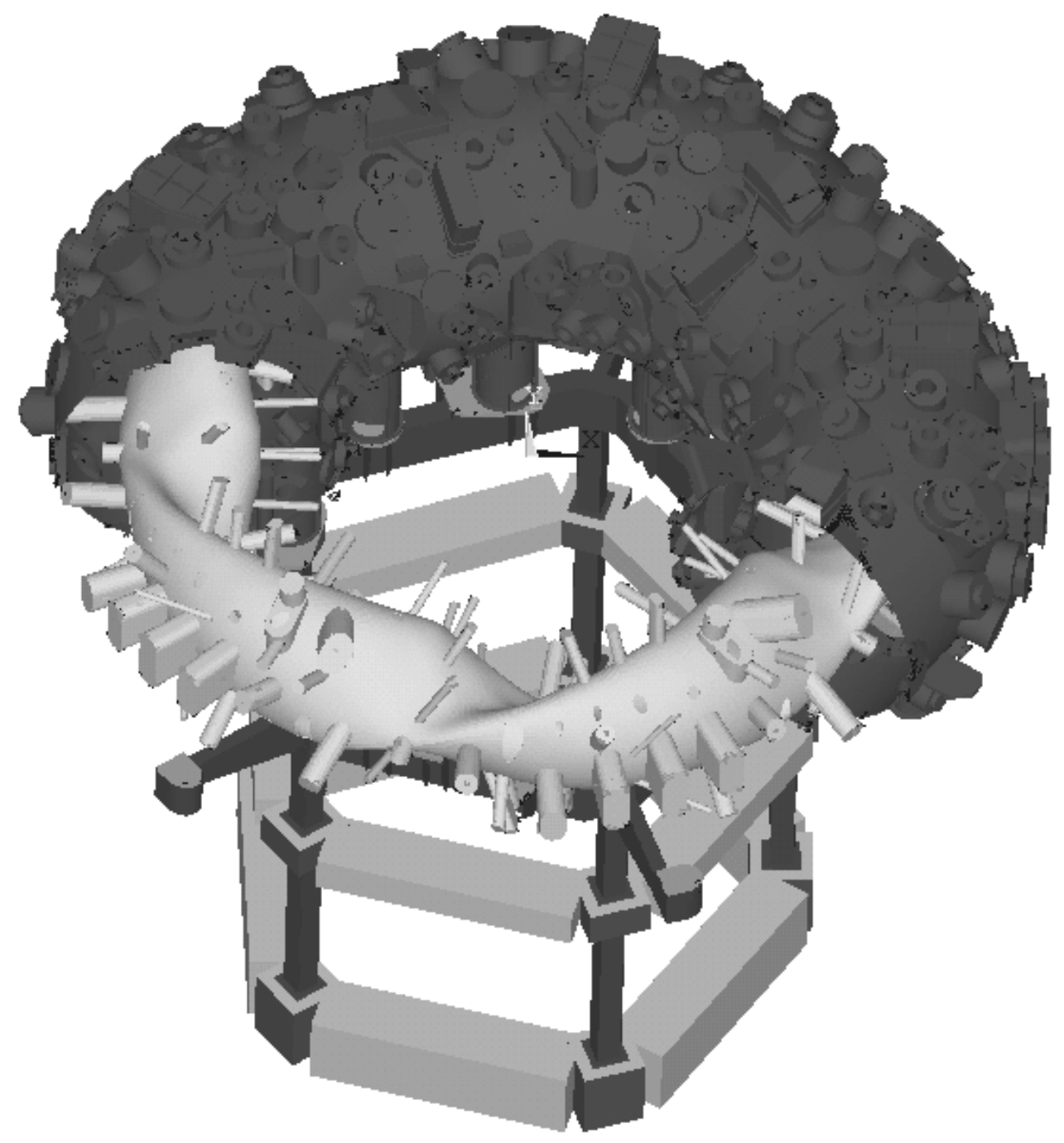

Figure 8. Simplified Global model of Cryostat system (2005). 


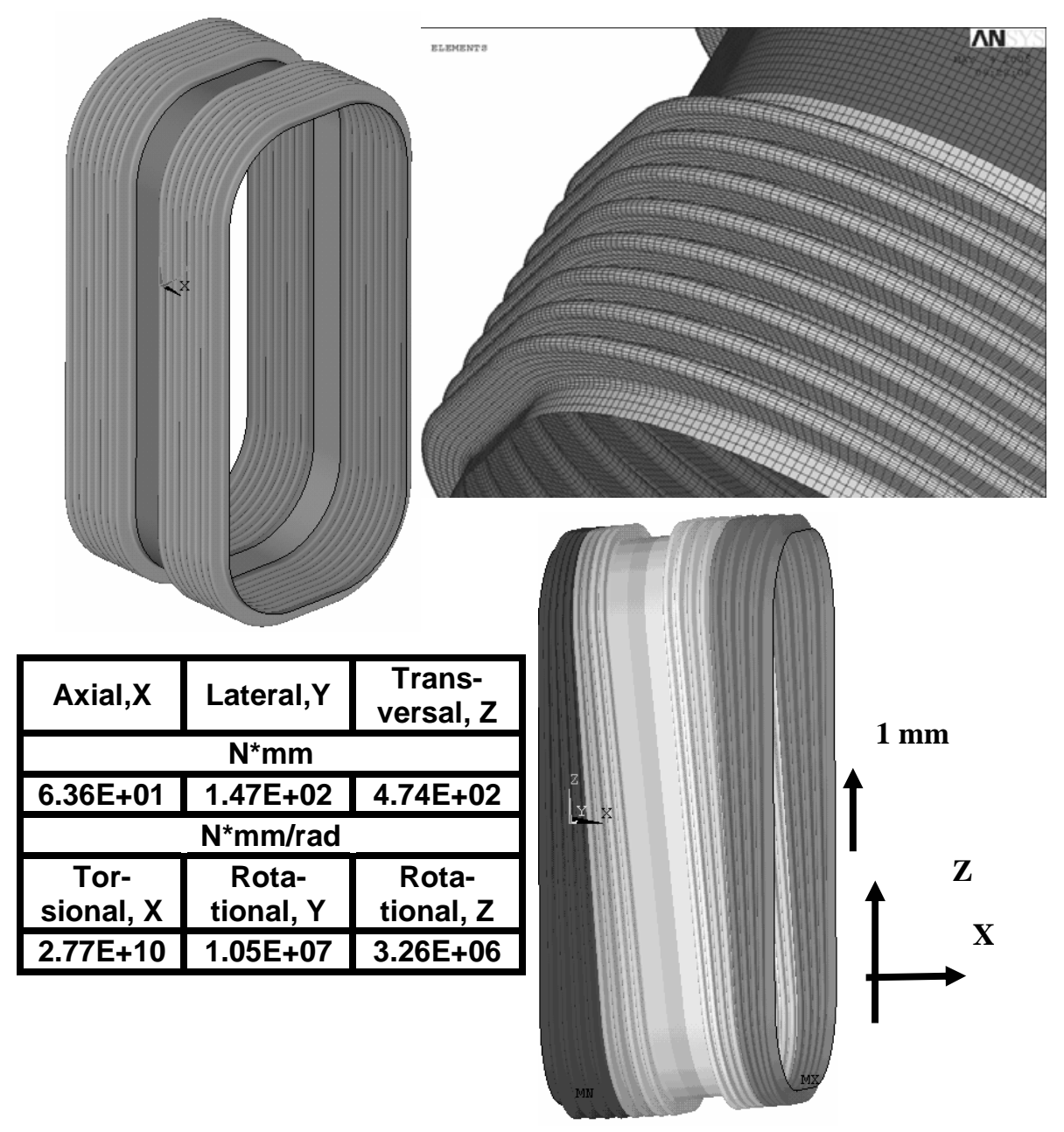

Figure 9. Numerical estimation of stiffness for rectangular bellows: finite element model (395000 ANSYS SHELL 63 elements), transversal stiffness calculation and defined stiffnesses 


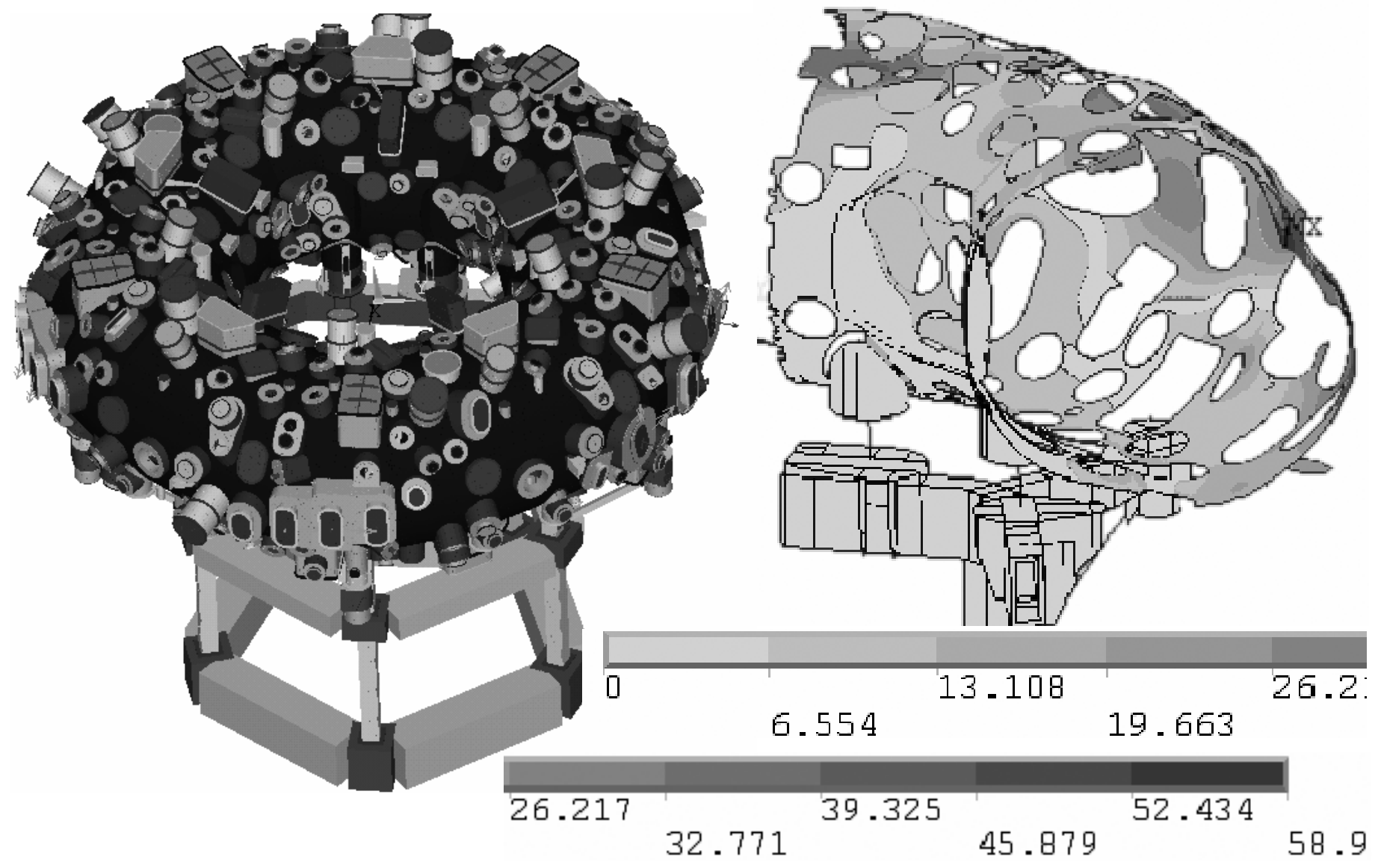

Figure 10. Non-linear buckling analysis of OV and MB: finite element model and deflection (mm) in case of rigid PV, elastic material properties and LAF of 6.5. 
TABLE 1. Narrow support Elements between NPC3 and NPC4

\begin{tabular}{|c|c|c|c|c|}
\hline Narrow & Pad & Initial & Maxi- & NSE pairs for coil 3 and 4 \\
\hline $\begin{array}{l}\text { Support } \\
\text { Element }\end{array}$ & $\begin{array}{l}\mathrm{OD}, \\
\mathrm{mm}\end{array}$ & $\begin{array}{l}\text { gap, } \\
\mathrm{mm}\end{array}$ & $\begin{array}{l}\text { mum } \\
\text { force, } \\
\text { MN }\end{array}$ & $\begin{array}{l}\text { PC3E4- } \\
\text { PC4E1 }\end{array}$ \\
\hline $\begin{array}{l}\text { NPC3E4 } \\
\text { NPC4E1 }\end{array}$ & 60 & 0.5 & 303 & \\
\hline $\begin{array}{l}\text { NPC3E5 } \\
\text { NPC4E2 }\end{array}$ & 60 & 1.0 & 245 & \\
\hline $\begin{array}{l}\text { NPC3E6 } \\
\text { NPC4E3 }\end{array}$ & 73 & 1.0 & 722 & \\
\hline $\begin{array}{l}\text { NPC3E10 } \\
\text { NP4-E5 }\end{array}$ & 60 & 0.0 & 334 & \\
\hline $\begin{array}{l}\text { NP3-E11 } \\
\text { NP4-E6 }\end{array}$ & 60 & 0.0 & 0 & $\begin{array}{l}\text { NPC3E6- } \\
\text { NPC4E3 }\end{array}$ \\
\hline $\begin{array}{l}\text { NP3-E12 } \\
\text { NP4-E7 }\end{array}$ & 60 & 0.0 & 3 & \\
\hline
\end{tabular}


TABLE 2. Design values of forces and moments for NPC CSEs

\begin{tabular}{|c|c|c|c|c|c|}
\hline \multirow{2}{*}{\multicolumn{2}{|c|}{$\begin{array}{c}\text { Coil } \\
\text { top/bottom } \\
\text { CSE }\end{array}$}} & $\begin{array}{c}\mathbf{F} \\
\text { axial }\end{array}$ & $\begin{array}{c}\mathbf{F} \\
\text { shear }\end{array}$ & $\begin{array}{c}\mathbf{M} \\
\text { torsion }\end{array}$ & $\begin{array}{c}\text { M } \\
\text { bending }\end{array}$ \\
\hline & & \multicolumn{2}{|c|}{ (MN) } & \multicolumn{2}{|c|}{ (MN m) } \\
\hline \multirow{2}{*}{ NPC 1} & top & 1.7 & 1.6 & 0.15 & 0.38 \\
\hline & bot & -4.4 & .99 & 0.005 & 0.29 \\
\hline \multirow{2}{*}{ NPC 2} & top & -1.4 & 1.3 & 0.17 & 0.31 \\
\hline & bot & -.64 & 1.3 & 0.044 & 0.19 \\
\hline \multirow{2}{*}{ NPC 3} & top & -1.3 & .93 & 0.16 & 0.18 \\
\hline & bot & -3.3 & 1.3 & 0.036 & 0.26 \\
\hline \multirow{2}{*}{ NPC 4} & top & .33 & 1.1 & 0.028 & 0.062 \\
\hline & bot & -2.5 & 1.0 & 0.056 & 0.13 \\
\hline \multirow{2}{*}{ NPC 5} & top & \pm 0.1 & .96 & 0.030 & 0.12 \\
\hline & bot & 1.9 & .17 & 0.40 & 0.019 \\
\hline
\end{tabular}


TABLE 3. Design values of forces and moments for LSEs

\begin{tabular}{|c|c|c|c|c|}
\hline \multirow[t]{2}{*}{ Coils } & $\mathbf{F}_{\text {axial }}$ & $\mathbf{F}_{\text {shear }}$ & $\mathbf{M}_{\text {torsion }}$ & $M_{\text {bending }}$ \\
\hline & \multicolumn{2}{|c|}{$(\mathrm{MN})$} & \multicolumn{2}{|c|}{$(\mathrm{MN} \mathrm{m})$} \\
\hline $\begin{array}{c}\text { NPC } \\
1-1\end{array}$ & $\begin{array}{c}-0.71 / \\
0.41\end{array}$ & 1.7 & 0.064 & 0.14 \\
\hline $\begin{array}{c}\text { NPC } \\
1-2 \\
\end{array}$ & $\begin{array}{c}-0.13 / \\
0.44 \\
\end{array}$ & 0.95 & 0.088 & 0.18 \\
\hline $\begin{array}{c}\text { NPC } \\
2-3\end{array}$ & 0.32 & 0.87 & 0.15 & 0.19 \\
\hline $\begin{array}{c}\text { NPC } \\
3-4 \\
\end{array}$ & $\begin{array}{c}-0.15 / \\
0.12 \\
\end{array}$ & 0.89 & 0.064 & 0.14 \\
\hline $\begin{array}{c}\text { NPC } \\
4-5 \\
\end{array}$ & -1.1 & 1.3 & 0.065 & 0.17 \\
\hline $\begin{array}{c}\text { NPC } \\
4-5 \\
\end{array}$ & -1.3 & 1.3 & 0.030 & 0.20 \\
\hline
\end{tabular}

